\title{
Analysis of Early Cone Dysfunction in an In Vivo Model of Rod-Cone Dystrophy
}

\author{
Mark M. Hassall 1,*® , Michelle E. McClements ${ }^{1} @$, Alun R. Barnard ${ }^{1,2}$, Maria I. Patrício ${ }^{1}$, \\ Sher A. Aslam ${ }^{1,2}$ and Robert E. Maclaren 1,2 \\ 1 Nuffield Laboratory of Ophthalmology, Department of Clinical Neurosciences, University of Oxford, \\ Oxford OX3 9DU, UK \\ 2 Oxford Eye Hospital, Oxford University Hospitals NHS Foundation Trust, Oxford OX3 9DU, UK \\ * Correspondence: enquires@eye.ox.ac.uk; Tel.: +61-426-732-991
}

Received: 9 August 2020; Accepted: 20 August 2020; Published: 22 August 2020

\begin{abstract}
Retinitis pigmentosa (RP) is a generic term for a group of genetic diseases characterized by loss of rod and cone photoreceptor cells. Although the genetic causes of RP frequently only affect the rod photoreceptor cells, cone photoreceptors become stressed in the absence of rods and undergo a secondary degeneration. Changes in the gene expression profile of cone photoreceptor cells are likely to occur prior to observable physiological changes. To this end, we sought to achieve greater understanding of the changes in cone photoreceptor cells early in the degeneration process of the $R \mathrm{ho}^{-/-}$mouse model. To account for gene expression changes attributed to loss of cone photoreceptor cells, we normalized PCR in the remaining number of cones to a cone cell reporter (OPN1-GFP). Gene expression profiles of key components involved in the cone phototransduction cascade were correlated with tests of retinal cone function prior to cell loss. A significant downregulation of the photoreceptor transcription factor $\mathrm{Cr} x$ was observed, which preceded a significant downregulation in cone opsin transcripts that coincided with declining cone function. Our data add to the growing understanding of molecular changes that occur prior to cone dysfunction in a model of rod-cone dystrophy. It is of interest that gene supplementation of $C R X$ by adeno-associated viral vector delivery prior to cone cell loss did not prevent cone photoreceptor degeneration in this mouse model.
\end{abstract}

Keywords: retina; cone photoreceptors; retinitis pigmentosa; rod-cone dystrophy; gene therapy

\section{Introduction}

Retinitis pigmentosa (RP) is an incurable inherited retinal disease (IRD) that affects approximately 1 in 4000 people [1] and it most commonly arises from genetic mutations in genes specific to rod photoreceptor cells. It is a rod-cone dystrophy, beginning with rod degeneration and the loss of night vision and peripheral vision. The cone photoreceptor cells then undergo secondary degeneration. In many forms of RP, this secondary cell loss occurs despite the mutated gene not being expressed in cone photoreceptors. The loss of cone photoreceptors is often more debilitating than rod photoreceptor cells loss, as cone photoreceptors are responsible for the central field of vision, high acuity vision and color vision $[2,3]$.

The understanding of cone photoreceptor cell survival and health following the degeneration of rod photoreceptor cells is still being elucidated [4,5]. Studies of mouse models of RP have identified key components of cone photoreceptor cells but their influence on survival is still poorly understood $[5,6]$. $\mathrm{RP}$ can occur as a result of a sporadic mutation or from a variety of inheritance patterns. There are over 200 genes associated with RP (RetNet [7]) and a great variety of mutations identified in each gene. The heterogeneity of RP genotypes limits the ability to prepare appropriate gene therapy treatments for all patients. A common intervention approach to preserve cone cell function and prevent cone cell 
apoptosis would be valuable-a "mutation-independent" strategy. Such a broad treatment could be more widely applied than a narrow therapy targeting only a single mutant variant of RP. Although it would not address the loss of rod photoreceptors, it would potentially offer the opportunity to maintain central visual acuity. In order for this to be a viable gene therapy approach, a greater understanding of the molecular profile of cone photoreceptor cells prior to and during degeneration is critical.

Punzo et al. [8] performed a broad characterization of gene pathway changes in the retinal transcriptome across four mouse models of RP during cone cell death (Pde $6^{r d 1}, \mathrm{Pde}_{\mathrm{g}} \mathrm{g}^{-/}, \mathrm{Rho}^{-/-}$ and $\left.R h o^{\mathrm{P} 23 \mathrm{H}}\right)$. A third of the downregulated genes identified from microarray data were genes involved in metabolism. Opn1sw mRNA was downregulated across the different mouse lines, but a cone-specific control for cone cell loss was not included. No papers to date have yet examined changes in cone phototransduction gene expression and correlated those changes with changes in visual or electrophysiological phenotype.

This study measured the changes in expression of genes involved in the cone phototransduction cascade during the period of cone photosensitivity loss in the $R \mathrm{ho}^{-/-}$mouse model. The $R \mathrm{ho}^{-/-}$ mouse model used in this report also expressed GFP under the control of the OPN1 promoter in cone photoreceptor cells, providing a control in gene expression profiling that would account for the declining total retinal cone cell count over time in the $\mathrm{Rho}^{-/-}$mouse model.

This report identifies significant downregulation of the genes $C r x$ and Opn1sw relative to OPN1-GFP expression levels in the $\mathrm{RhO}^{--}$mouse model. These changes occurred prior to detectable changes in cone function and survival. As broad therapeutic approaches are being pursued that might preserve cone photoreceptor cells following primary loss of rod photoreceptor cells, we were interested to identify key regulators that might determine cone cell fate. Since $C r x$ acts upstream of $O p n 1$, we tested the hypothesis that reversing $\mathrm{Cr} x$ downregulation might delay cone cell death when occurring secondary to rod loss in the $\mathrm{Rho}^{-/-}$mouse model. This did not however prevent cone cell degeneration, implying that downregulation of cone-specific genes such as $\mathrm{Cr} x$ may be a global secondary effect of cone stress rather than being primary drivers of cone cell degeneration.

\section{Results}

\subsection{Gene Expression Analysis of Cone Phototransduction Genes Over Time in the Rho ${ }^{-/-}$OPN1-GFP Mouse Model}

To provide an understanding of the changes in the expression profile over time for genes involved in the cone phototransduction cascade, tissue samples were collected from age-matched Rho ${ }^{-/-}$OPN1-GFP mice and wild-type OPN1-GFP mice. Target genes for qPCR analysis were: Opn1mw, Opn1sw, Pde6h, Crx , Cnga3, Cngb3 and Arr3, as well as the cone GFP reporter and ActB control genes.

Expression of cone GFP did decline from baseline in the Rho ${ }^{-/}$OPN1-GFP model between the PNW2 and PNW25 time points ( $p=0.043$; Supplementary Figure S1a). However, changes in cone GFP expression were not significantly different between the OPN1-GFP and Rho ${ }^{-/-}$OPN1-GFP models $(p=0.091)$ at any time point. Expression of Rho was significantly different between the OPN1-GFP and Rho ${ }^{-/}$OPN1-GFP models at all timepoints $(p<0.001$; Supplementary Figure S1b). Detection of all genes were then normalized to levels of the two reference genes $A c t B$ and GFP per sample and then compared to levels in the PNW2 OPN1-GFP samples (Figure 1a), as well as OPN1-GFP samples at the equivalent PNW time point (Figure 1b), using the $2^{-\Delta \Delta C t}$ method (Appendix A) [9]. These data comparisons revealed the change in gene expression profile over time for both the wild-type OPN1-GFP model and the Rho ${ }^{-/-}$OPN1-GFP mouse model. Statistical analyses of the qPCR gene expression data were conducted using a non-linear regression model, full details are available in Supplementary Figure S2 and Supplementary Table S1. 
a
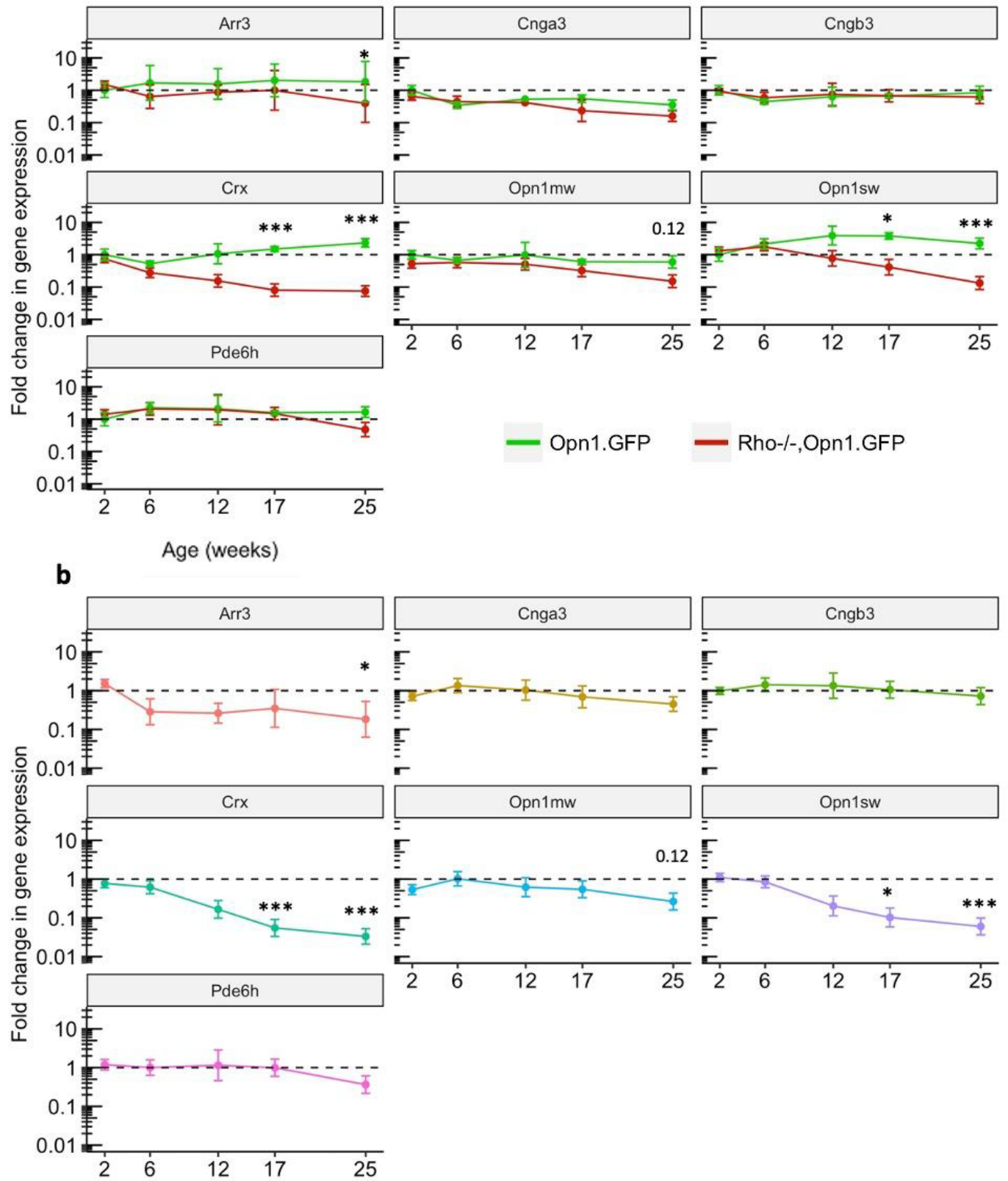

Age (weeks)

Figure 1. Gene expression analysis of cone phototransduction genes. (a) Gene expression data over time (post-natal week, PNW, 2, 6, 12, 17 and 25) showing $2^{-\Delta \Delta \mathrm{Cq}}$ values for $R h o^{-/-O P N 1-G F P}$ mice and OPN1-GFP mice. $\triangle \triangle \mathrm{Ct}$ values calculated by double normalizing the test gene to the mean of $A c t B$ and GFP reference gene levels, then comparing each time point against OPN1-GFP mouse expression levels at PNW2 baseline. The dotted line represents the gene expression baseline of OPN1-GFP mice at PNW2 for each gene. Crx and Opn1sw genes show significantly different reduced expression patterns at PNW17 and PNW25, a trend that is already emerging at PNW12. The other genes are not significantly different between genotypes, but many do significantly change from PNW2 baseline. (b) The same gene expression data, displaying $\Delta \Delta \mathrm{Ct}$ values calculated by double normalizing the test gene to the mean of $A c t B$ and GFP reference gene levels, then comparing each time point against OPN1-GFP mouse expression levels at the same time point (OPN1-GFP1 values represented by the dotted line). Full statistical model results available in Supplementary Table S1; All values are mean \pm SEM. Tissue samples collected at PNW2 (OPN1-GFP $n=8, \mathrm{Rho}^{-/-}$OPN1-GFP $n=8), \operatorname{PNW6}(n=3, n=5), \operatorname{PNW} 12,(n=3, n=3), \operatorname{PNW} 17(n=3, n=4)$, and PNW25 $(n=3, n=3)$. * denotes $p<0.05$, ${ }^{* * *}$ denotes $p<0.001$. 
OPN1-GFP mice did not show significantly reduced expression of any gene over time. $\mathrm{Rho}^{--}$OPN1-GFP mice showed significantly reduced expression of Crx , Opn1sw, Opn1mw, Arr3, Cnga3 and Pde6h genes at PNW25 when compared to the PNW2 baseline. Crx declined significantly from baseline from PNW6 onwards $(p<0.001)$. Opn1sw and Cnga3 declined from baseline by PNW17 $(p<0.001$ and $p<0.05$ respectively). Expression levels were significantly different between the two mouse models for Crx at PNW17 $(p<0.001)$ and PNW25 $(p<0.001)$, Opn1sw at PNW17 $(p<0.05)$ and PNW25 $(p<0.001)$, and Arr3 at PNW25 $(p<0.05)$. The difference between the two genotypes was not significant for Opn1mw at any time point. Downregulation of $C r x$ in Rho ${ }^{-/-}$OPN1-GFP mice showed a seven-fold decline from baseline by PNW 12 and by 30-fold by PNW 17. The Opn1sw gene was the most downregulated of the two cone opsins, demonstrating a significant 16 -fold reduction in expression by PNW 17 whereas Opn1mw declined five-fold by PNW 17 (not significant between genotypes). Analysis of the cone genes are presented in detail in Supplementary Table S1.

\subsection{Characterization of the $\mathrm{Rho}^{-/-}$OPN1-GFP Mouse Model Phenotype}

The natural history of retinal architecture degeneration was measured using OCT of both eyes in $R h o^{-/-}$OPN1-GFP mice prior to sacrifice at timepoints of PNW6, 12, 17, and 25. Figure 2 shows that the outer retinal thickness of OPN1-GFP controls varied minimally from baseline and did not change significantly between PNW6 and PNW50 ( $p=0.40$, linear model). Similarly, no differences in outer retinal thickness were evident on the superior-inferior axis at the different time points when measured $750 \mu \mathrm{m}$ from the nerve head. In Rho ${ }^{-/-}$OPN1-GFP mice, the outer retina was significantly different between PNW6 and PNW12 $(p<0.001)$, as well as between PNW12 and PNW17 $(p<0.001)$. The $R h 0^{-/}$OPN1-GFP outer retina was unmeasurable on OCT by 17 weeks of age. The rate of thinning was equal for both superior and inferior retina $(p=0.36)$. In Rho-l-OPN1-GFP mice, after loss of the outer retina, the total retinal thickness at PNW $17(116.5 \pm 10.0 \mu \mathrm{m})$ did not thin significantly by PNW $25(117 \pm 17.4 \mu \mathrm{m})$, demonstrating that the degeneration detected with OCT was confined to the outer retina. The sensitivity of qPCR to detect remaining rod photoreceptor cells outperforms in vivo OCT imaging. The residual mutant Rho transcript detected in Supplementary Figure S1b persists long after the outer nuclear layer of rod photoreceptors is no longer detectable on OCT (Figure 2a).

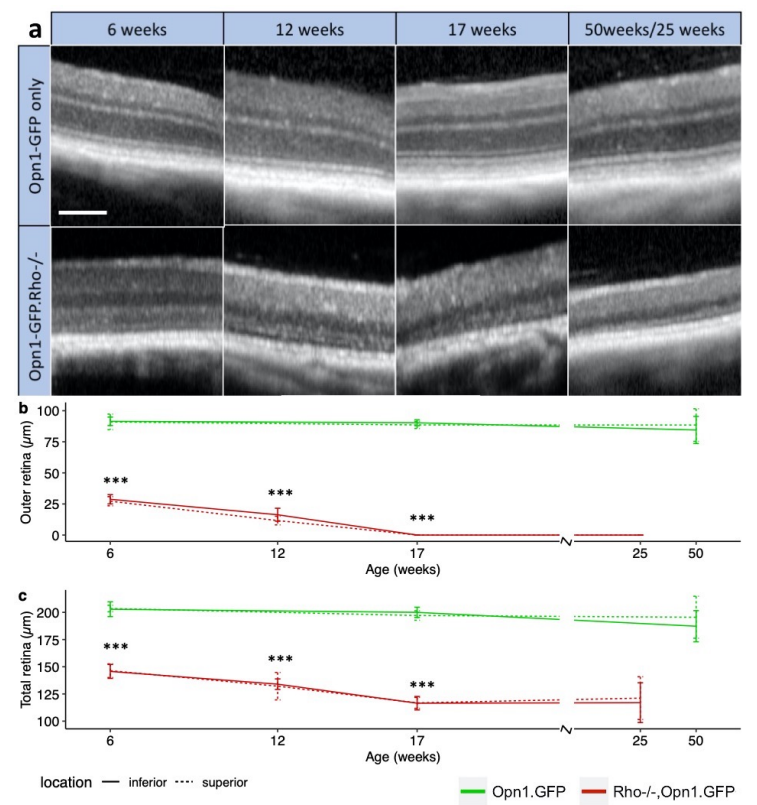

Figure 2. Changes in retinal structural in $\mathrm{Rho}^{-/}$OPN1-GFP mice. (a) Representative OCT images for $\mathrm{Rho}^{-/-}$OPN1-GFP mice and OPN1-GFP controls at each time point, showing the loss of outer retina. White scale bar $=100 \mu \mathrm{m}$. 
(b) Degeneration of the outer retinal thickness and (c) total retinal thickness measured on OCT for Rho-l-OPN1-GFP mice (red) occurs rapidly and differs from non-degenerate OPN1-GFP mice (green) as early as PNW6. Total retinal thickness was measured from the inner margin of the nerve fiber layer to the inner margin of the RPE. Outer retinal thickness was measured from the inner margin of the outer nuclear layer to the inner margin of the RPE. ${ }^{* * *}$ denotes $p<0.001$; values are mean \pm SEM. Tissue collected from Rho-l- OPN1-GFP PNW 6 ( $n=7$ mice), PNW $12(n=3)$, PNW $17(n=8)$, and PNW 25 $(n=3)$ and in wild-type OPN1-GFP mice at PNW $6(n=4)$, PNW $17(n=6)$ and PNW $50(n=2)$.

Given the known loss of retinal structure in the $\mathrm{Rho}^{-/-}$mouse model [10], for additional information relating to the degeneration of cone photoreceptor cells in this model, we used the OPN1-GFP reporter locus to assess the cone cell marker using en face cSLO imaging. Cone cells expressing OPN1-GFP are visible as fluorescent dots and manual counting of these correlates with the surviving number of GFP positive photoreceptors [11]. The natural history of cone photoreceptor degeneration was measured using cSLO in $\mathrm{Rho}^{-/-}$OPN1-GFP mice and OPN1-GFP mice at cross-sectional timepoints PNW 6, PNW 12, PNW 17, and PNW 25. Representative images are shown in Figure 3a indicating a loss of GFP positive cone cells in $R \mathrm{ho}^{-/-}$OPN1-GFP mice over time. Manual counting of the fluorescent dots from standardized images (Figure $3 b$ ) revealed that $R h o^{-/}$OPN1-GFP mice began with equivalent GFP positive cells as OPN1-GFP controls $(p=0.74)$. Rho ${ }^{-/}$OPN1-GFP mouse cell count then declined over time $(-1.1 \pm 0.1$ cells/day) and approached zero at 25 weeks (34 \pm 18$)$. OPN1-GFP mice had stable cell counts at PNW6, 12, and 17.
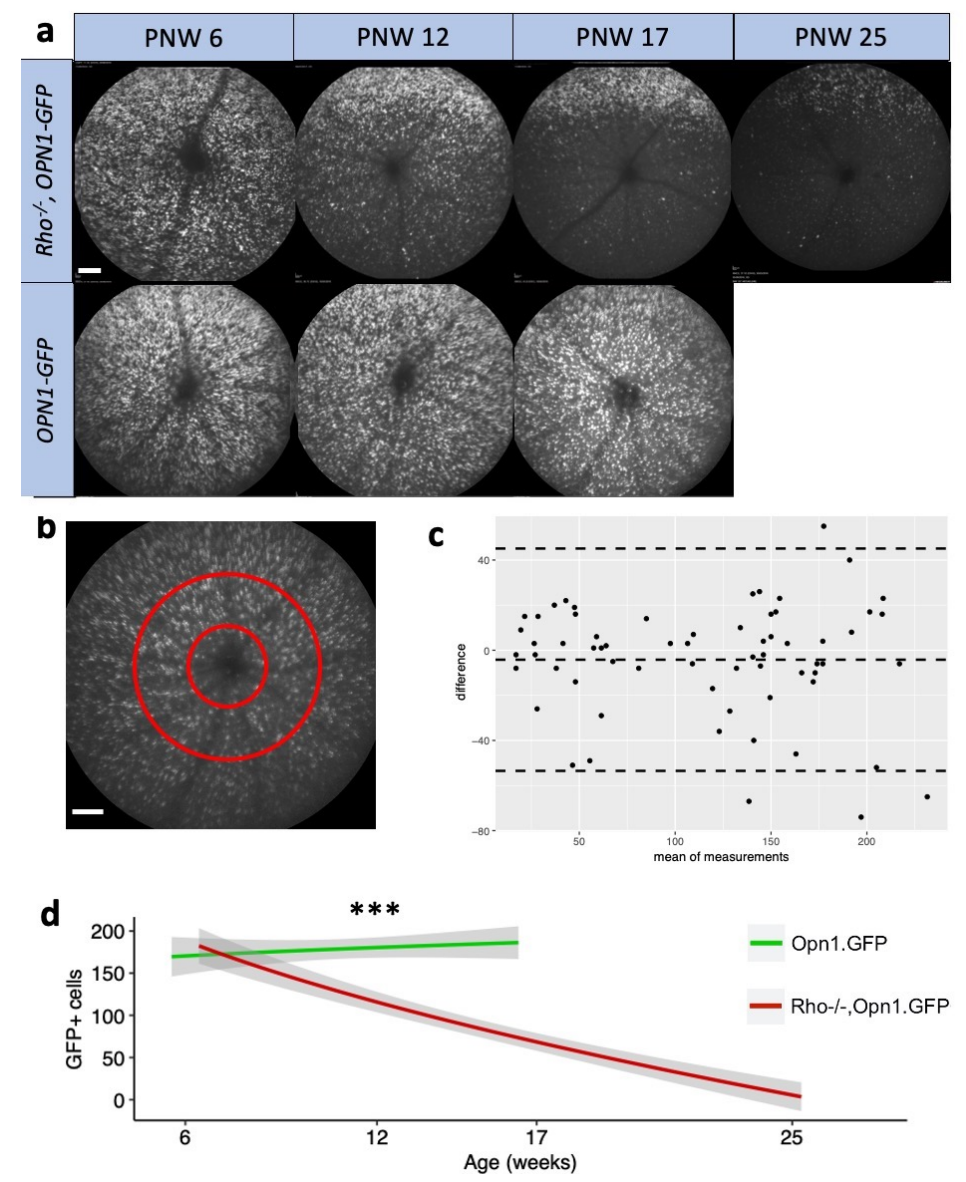

Figure 3. Changes in GFP positive cone photoreceptor cells in $R h o^{-/-}$OPN1-GFP mice. (a) Representative cSLO images demonstrating that $\mathrm{Rho}^{-/-}$OPN1-GFP mice show a decline in GFP positive cone cells in vivo, compared to the steady cone population in the OPN1-GFP mice. 
Representative images demonstrate the gross pattern of in vivo GFP positive cone cell loss in Rho ${ }^{-/}$OPN1-GFP mice. White scale bar $=0.1 \mathrm{~mm}(\mathbf{b})$ To quantify the magnitude of loss of cones, a central annulus was sampled for manual particle counts using the ImageJ counter plugin. White scale bar $=0.1 \mathrm{~mm}$ (c) Bland-Altman plot showing the difference in manual counts between the left and right eyes across the mice shows no obvious systematic error. Some mice had substantial inter-eye differences of GFP-positive cone cells, which is similar to the asymmetric progression of IRDs observed in humans. (d) Manual cell counts of fluorescent GFP cells in en face cSLO images of the retina showing loss of cone GFP signal in Rhol- OPN1-GFP mice and OPN1-GFP mice at cross-sectional timepoints PNW 6 ( $n=9$ mice; $n=9$ mice respectively), PNW $12(n=5 ; n=4)$, PNW $17(n=12 ; n=5)$, and PNW $25(n=6 ; n=0) .{ }^{* * *}$ denotes $p<0.001$; values are mean cell count $\pm 95 \% \mathrm{CI}$ (grey band).

With the loss of GFP positive photoreceptors and loss in outer retinal structure over time, we further tested cone function using a light-adapted ERG protocol [12]. Rho-/- OPN1-GFP mice were assessed at PMW 6, PNW 12, PNW 17, and PNW 25. The b-wave amplitudes elicited by a range of flash stimulus ( -0.5 to $1.5 \log \mathrm{cd} . \mathrm{s} / \mathrm{m}^{2}$ ) in photopic conditions for these mice are shown in Figure $4 \mathrm{a}, \mathrm{b}$. In The cone-specific b-wave of the Rho-/- OPN1-GFP mice at PNW $6(137 \pm 90 \mu \mathrm{V})$ was significantly reduced from baseline (PNW 6) by PNW $17(6 \pm 6 \mu \mathrm{V}, p<0.001)$ and PNW $25(3 \mu \mathrm{V} \pm 9 \mu \mathrm{V}, p<0.001)$, but not significantly reduced at PNW $12(52 \pm 14 \mu \mathrm{V}, p=0.12)$.
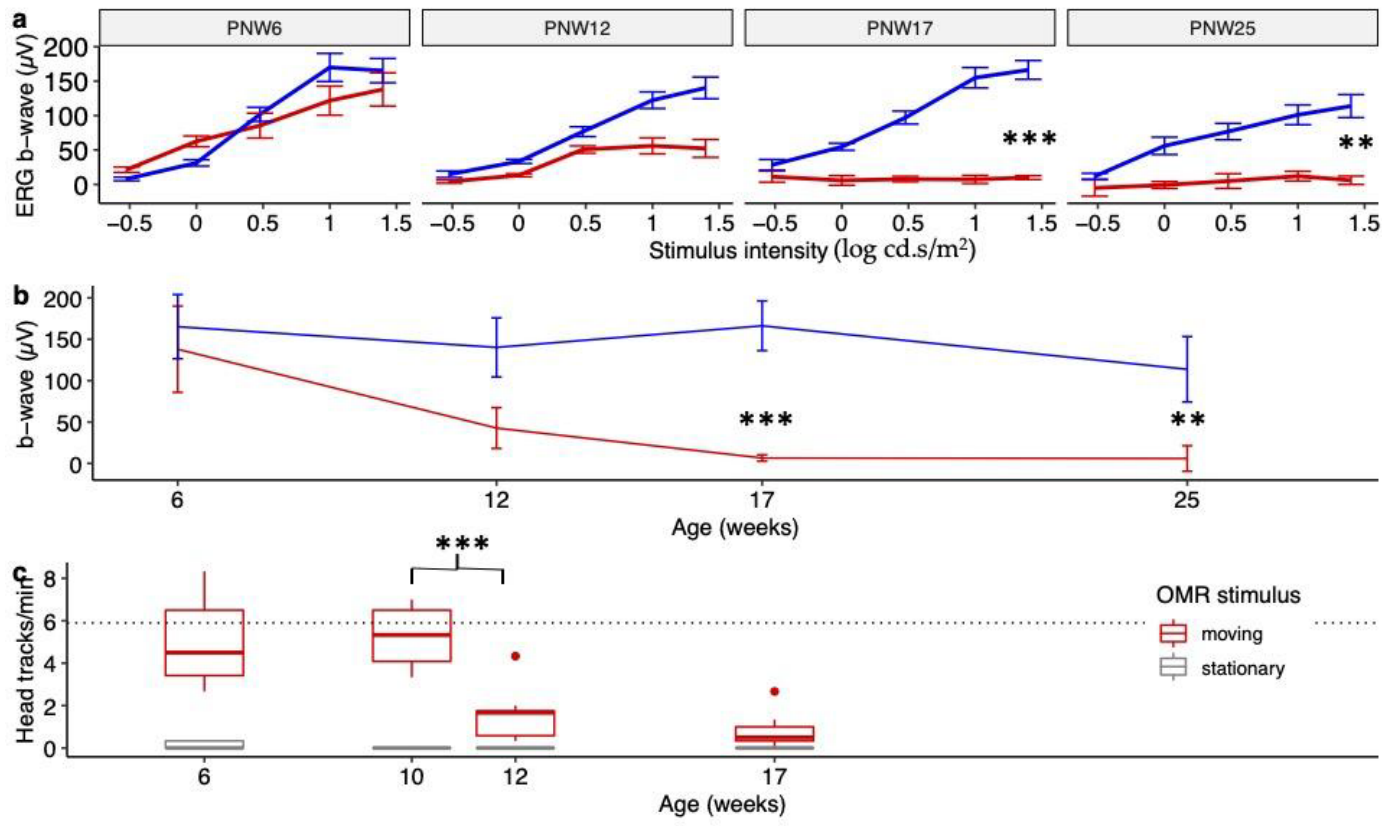

w w $\quad$ Rho-/-,Opn1.GFP

Figure 4. Changes in retinal function in $R h \mathrm{o}^{-/-}$OPN1-GFP mice. (a) Light-adapted ERG b-wave amplitudes for a range of stimulus intensities (-0.5 to $\left.1.5 \log \mathrm{cd} . \mathrm{s} / \mathrm{m}^{2}\right)$ comparing $R h o^{-/-}$OPN1-GFP mice and wild-type mice at PNW $6(n=7 ; n=6$, respectively), PNW $12(n=2 ; n=5)$, PNW 17 ( $n=7$; $n=6)$ and PNW $25(n=3 ; n=4)$. ${ }^{* * *}$ denotes $p<0.001$; ${ }^{* *}$ denotes $\mathrm{p}<0.01$; All values mean \pm SEM. (b) The same ERG data, displaying only the light-adapted ERG b-wave amplitudes for $1.5 \log \mathrm{cd} . \mathrm{s} / \mathrm{m}^{2}$ flash stimulus for both mouse strains over time. There is rapid loss of cone function in $R h^{-/}$OPN1-GFP mice. All values mean \pm SEM. (c) OMR photopic head-tracking behavior in Rho ${ }^{-1}$ OPN1-GFP mice at PNW 6 ( $n=5$ mice), PNW $12(n=3)$, PNW $17(n=4)$, and PNW $25(n=5)$. Loss of head tracking occurs between 10 and 12 weeks $(p<0.001$ ). Null-stimulus OMR test conditions provided as controls (grey boxes) and ' $\mathrm{wt}^{\prime}$ ' OPN1-GFP mouse head-tracking behavior provided as healthy reference (dotted line). All values $\mathrm{IQR} \pm 95 \% \mathrm{CI}$, points represent outliers. 
For further understanding of the influence of the progressive cone dysfunction in the Rho-l-OPN1-GFP mouse model over time, head-tracking behavior under photopic conditions was assessed at PNW 6 ( $n=10$ eyes), PNW $10(n=4$ eyes), PNW $12(n=8$ eyes $)$ and PNW 17 ( $n=10$ eyes), Figure 4c. At the 6 week baseline time point, head-tracking of $5.1 \pm 2.1$ per minute under photopic conditions was significantly different compared to the stationary stimulus null test conditions $(0.13 \pm 0.08 ; p<0.001)$ and was equivalent to responses achieved from mice with no retinal degeneration. Head-tracking behavior did not change significantly from baseline to 10 weeks of age $(5.2 \pm 1.7, p<0.001)$ but at 12 weeks of age was reduced significantly to $1.6 \pm 1.3(p<0.01)$, although this remained significantly higher than the null stimulus condition $(p=0.04)$. The distinction between positive and null test condition head-tracking behavior was lost at 17 weeks $(0.8 \pm 0.8 ; 0 \pm 0.2 ; p=0.23)$.

\subsection{CRX Gene Supplementation in Rho-l-OPN1-GFP Mice}

By characterizing the progression of changes in cone function in Rho-l-OPN1-GFP mouse model, we identified that a downregulation in expression of $\mathrm{Crx}$ preceded structural and functional changes in cone photoreceptor cells. Gene therapy strategies that aim to preserve and prevent cone loss in rod-cone dystrophies are of great interest and in line with this broad treatment approach, we generated an rAAV.CRX construct. This vector was validated and delivered as described in the methods and Supplementary Figure S4. Mice received injections of rAAV.CRX and in vivo testing at timepoints described in Supplementary Figure S5. In an attempt to counter the loss of cone photoreceptor cells by early intervention of their gene expression profile, $R h \mathrm{O}^{-/-}$OPN1-GFP mice were injected at PNW3. Evidence of increased $C R X$ mRNA expression above native $C r x$ expression was achieved by qPCR Figure $5 \mathrm{a}$, three weeks after subretinal injection of a high dose $\left(1.5 \times 10^{8} \mathrm{gc} ; n=4\right)$, low dose rAAV.CRX $\left(1.5 \times 10^{7} \mathrm{gc} ; n=4\right)$, and PBS sham $(n=4)$. The $2^{-\Delta \Delta \mathrm{Ct}}$ method was used to normalize expression to the $A c t B$ reference gene and against the fellow uninjected eye, before comparing between treatment groups. Treatment with $1.5 \times 10^{8}$ gc of rAAV.CRX showed a significant increase (6.5-fold) in CRX/Crx gene expression compared to sham injected eyes (1.2-fold; $p=0.044)$ but no significant change in expression was observed in mice treated with $1.5 \times 10^{7} \mathrm{gc}(p=0.51)$.

Three antibodies to CRX were tested for species-specific labelling (Abcam, Camrbidge, UK, AB54635; SantaCruz, Dallas, TX, USA, SC-81958; Thermo Fisher Scientific, Waltham, MA, USA, PA5-32182) but none were able to fully distinguish between orthologous mouse and human proteins. Subretinal injections of rAAV.CRX $\left(1.5 \times 10^{8} \mathrm{gc}\right)$ caused a marked increase in detectable CRX signal in photoreceptors and cells of the inner nuclear layer Figure $5 b$,c. A dose-dependent gradient from the site of superior retinal injection was apparent with less CRX signal in the inferior retina, as well as compared to uninjected eyes (Figure $5 \mathrm{~d}-\mathrm{g}$ ). 

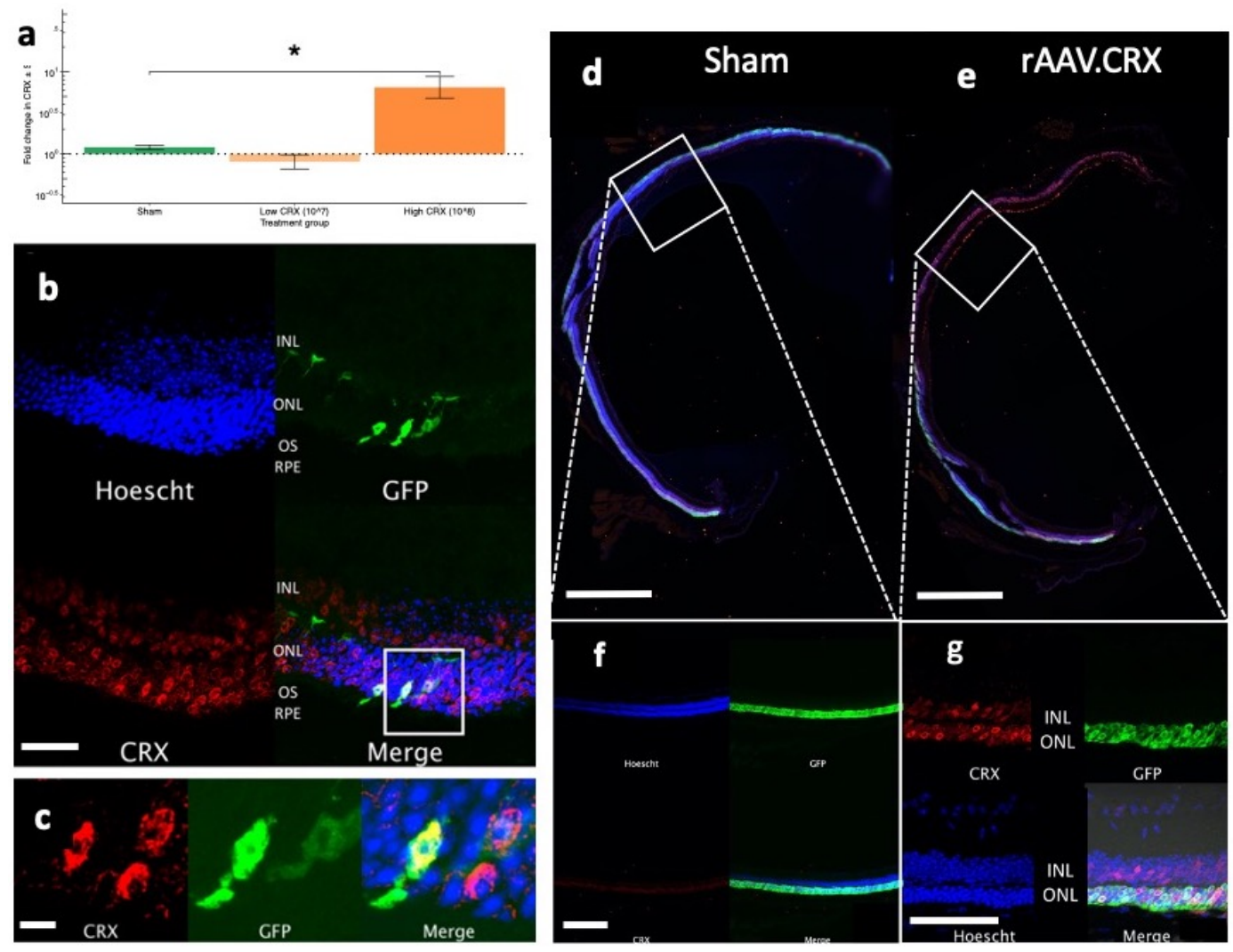

Figure 5. CRX transgene overexpression by subretinal rAAV injections. (a) Fold-change in CRX gene expression in Rho ${ }^{-/}$OPN1-GFP mouse retinas injected with high dose rAAV.CRX $\left(1.5 \times 10^{8} \mathrm{gc}\right.$; dark orange; $n=4)$, low dose rAAV.CRX $\left(1.5 \times 10^{7}\right.$ gc; light orange; $\left.n=4\right)$ or sham PBS (green; $\left.n=4\right)$. A significant increase occurred in only the $1.5 \times 10^{8}$ gc treated retinas. * denotes $p<0.05$ compared to sham eyes. All values mean \pm SEM. (b) Superior retina of an rAAV.CRX $\left(1.5 \times 10^{8} \mathrm{gc}\right)$ treated eye in an $\mathrm{Rho}^{-/-}$, OPN1-GFP mouse sacrificed at PNW 10 (7 weeks following surgery). Nuclear-specific Crx staining is seen throughout the outer nuclear layer and, more lightly, in the inner nuclear layer. Scale bar $=25 \mu \mathrm{m}$ (c) Enlarged area of interest showing colocalization of CRX with endogenous GFP in cone photoreceptors, confined to the nuclei and not extending into the outer segment. CRX staining also occurs in other non-GFP labelled nuclei which are likely rod cells. Scale bar $=5 \mu \mathrm{m}(\mathbf{e}, \mathbf{g}) \mathrm{rAAV}$.CRX $\left(1.5 \times 10^{8} \mathrm{gc}\right)$ injected pilot study $\mathrm{Rho^{-/ }} \mathrm{Nrl-GFP}$ retinas showing CRX staining in the ONL and INL. rAAV.CRX injected superior retinas showed a far stronger CRX staining pattern compared to the inferior retinas of the injected eyes, as well as contralateral sham injected eyes $(\mathbf{d}, \mathbf{f})$. Scale bars d,e both $=1 \mathrm{~mm}$. Scale bars $\mathrm{f}$, both $=50 \mu \mathrm{m}$.

\subsection{Phenotypic Changes to Rho-/-OPN1-GFP Mice Following Subretinal Injection of rAAV.CRX}

Assessments of outer retinal thickness revealed that gene supplementation with rAAV.CRX did not slow retinal thinning, Figure 6a. In addition to this, the treatment did not show evidence of in vivo cone cell rescue. There were no significant differences in the number of GFP-positive cells in cSLO retinal images of $\mathrm{Rho}^{-/-}$OPN1-GFP mice at 1 and 5 weeks post injection. The mean number of GFP-positive cells in sham injected retinas at week 1 post-injection $(179 \pm 23$ cells/area) and week 5 $(174 \pm 38)$, were not significantly different from high dose $\left(1.5 \times 10^{8}\right.$ gc AAV.CRX) injected retinas at week $1(132 \pm 48)$ or week $5(131 \pm 41, p=0.96)$. Nor were sham retinas different from low dose $\left(1.5 \times 10^{7} \mathrm{gc} \mathrm{AAV} . C R X\right)$ injected retinas at week $1(134 \pm 31)$ or week $5(108 \pm 39 ; p=0.76)$. 

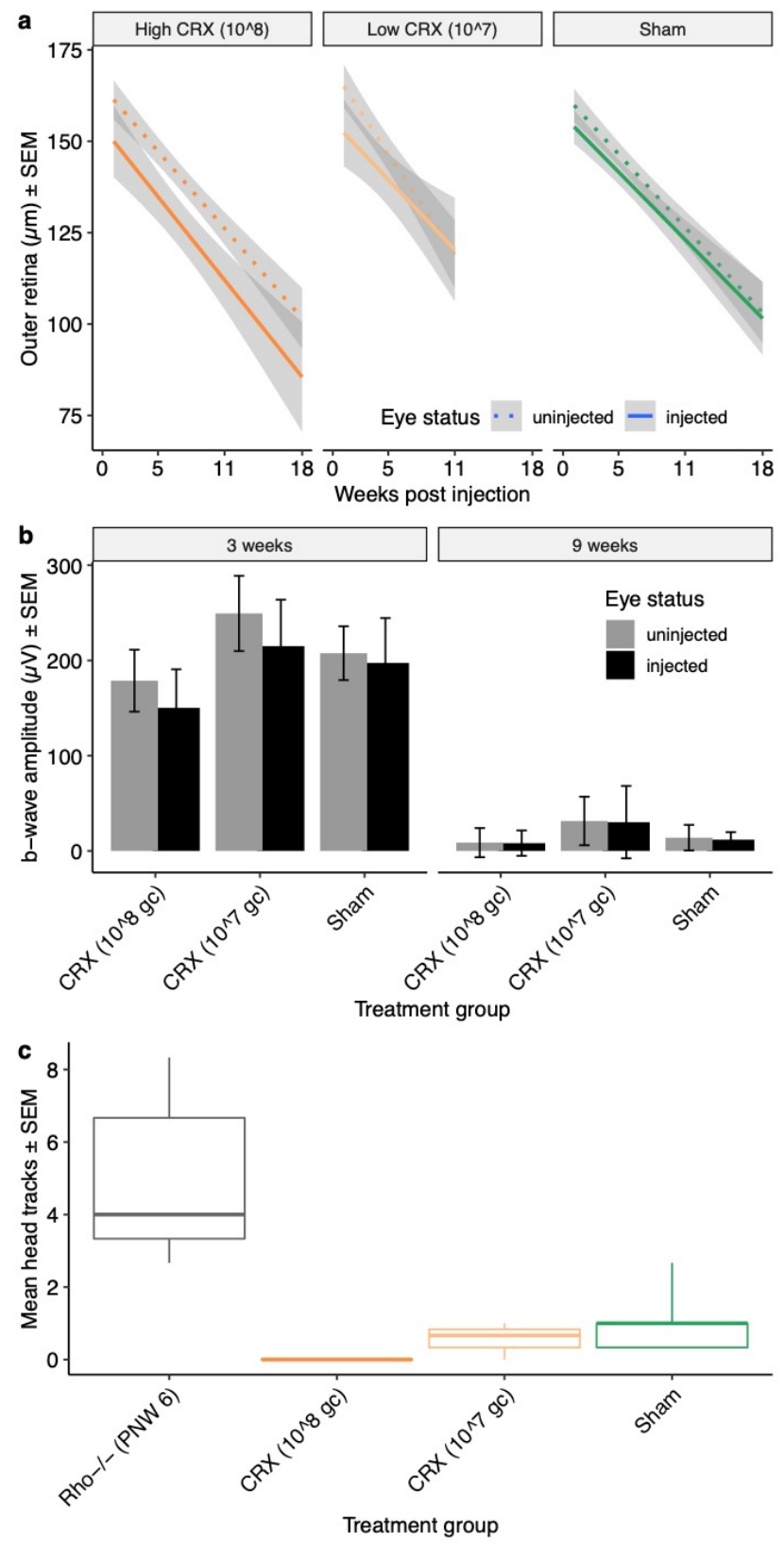

Figure 6. Rescue effect of rAAV.CRX on cone pathway function and retinal structure in $\mathrm{Rho}^{-/}$, OPN1-GFP mice. (a) Average thickness of superior the outer retina during the study period shows equivalent age-related decline in total retinal thickness of uninjected eyes. No group had slower outer retinal loss in the injected eye. All values are mean $\mu \mathrm{M} \pm 95 \%$ confidence intervals (grey band). (b) Light-adapted ERG response to $25 \mathrm{~cd} . \mathrm{s} / \mathrm{m}^{2}$ photopic flash stimulus at PNW 6 (3 weeks post injection) and PNW 12 (9 weeks post injection) in $\mathrm{Rho}^{-/-}$, OPN1-GFP mice, comparing b-waves of injected and uninjected eyes. None of the groups showed rescue of ERG function in injected eyes at PNW 12. All values are mean $\mu \mathrm{V} \pm \mathrm{SEM}$. (c) OMR in photopic testing conditions of $R h o^{-/-}$, OPN1-GFP mice 10 weeks following rAAV.CRX or PBS sham injection (PNW13). Uninjected $R h o^{-/}$, OPN1-GFP controls at PNW 6 ( $n=5$; grey) are included for comparison. There is limited head-tracking behavior in each of the treatment groups and no rAAV treatment group showed rescue of head-tracking behavior. (All values mean head tracks/minute \pm SEM bars. For each panel, treatments groups are high dose AAV.CRX $\left(10^{8} \mathrm{gc} / \mu \mathrm{L} ; \mathrm{n}=14\right.$ mice; dark orange $)$, low dose AAV.CRX $\left(10^{7} \mathrm{gc} / \mu \mathrm{L} ; \mathrm{n}=17\right.$ mice; light orange $)$ or PBS sham ( $\mathrm{n}=17$ mice; green). 
Light-adapted ERG assessments were performed to assess cone pathway function three weeks post-injection (PNW6), Figure $6 \mathrm{~b}$. At the $25(\log 1.5) \mathrm{cd} . \mathrm{s} / \mathrm{m}^{2}$ flash stimulus, there were no significant differences in the mean b-wave of uninjected eyes across all groups, demonstrating that the baseline characteristics of each group were similar. The $25 \mathrm{~cd} . \mathrm{s} / \mathrm{m}^{2}$ response of the PBS sham injected eyes did not differ significantly from uninjected fellow eyes at 3 weeks after injection $(197 \pm 22 \mu \mathrm{V}$, $207 \pm 13 \mu \mathrm{V}, p=0.53 ; n=17$ ), demonstrating that the sham injections did not have a significant effect on baseline function. Each group of treated eyes was normalized to fellow uninjected eyes and then compared to the sham injected mice at the $25 \mathrm{~cd} . \mathrm{s} / \mathrm{m}^{2}$ flash stimulus at 3 weeks post-injection using a linear model. The high dose $\left(1.5 \times 10^{8} \mathrm{gc}\right)$ and low dose $\left(1.5 \times 10^{7} \mathrm{gc}\right)$ cohorts showed no significant differences from the sham injected cohort. At 9 weeks post-injection (PNW12), the cone response was largely extinguished in all groups (consistent with the earlier natural history study) and there were no significant differences between injected and uninjected eyes for any group. There were also no significant differences in mean b-wave implicit time at any stimulus intensity between the injected eyes of each group.

Despite no rescue of cone photoreceptor structure or function, OMR testing in photopic conditions were also performed with $\mathrm{Rho}^{-/-}$OPN1-GFP mice 10 weeks post-injection (PNW 13). The untreated controls showed the expected head tracking behavior (median 4, IQR [3.3, 6.7]) but limited or no head-tracking behavior was recorded in each of the treatment groups (Figure 6c).

\section{Discussion}

This study details the timeline of cone function loss and the declining expression of cone phototransduction transcripts in the Rho-/- OPN1-GFP mouse. Data presented here show that cone ERG function in Rho ${ }^{-/}$OPN1-GFP mice declines precipitously between PNW6 and PNW12, coinciding with loss of OMR head-tracking behavior between PNW10 and PNW12. The complete loss of cone function precedes the loss of GFP labelled cones demonstrated in vivo imaging by a number of months. Taken together, this suggests that dormant cone photoreceptors exist in the retina of RP mice long after the extinction of photosensitivity, Figure 7. Of interest, we identified that the $\mathrm{Cr} x$ gene was the first of the panel tested to be significantly downregulated. In an attempt to reactivate dormant cone photoreceptors we subsequently delivered $C R X$ to these mice but observed no improvements in cone photoreceptor survival or function. It is worth noting that cone photoreceptors constitute such a small proportion of the retinal cell population so that even a true cone rescue effect of a portion of retinal cone cells may not be detectable using these measurements.

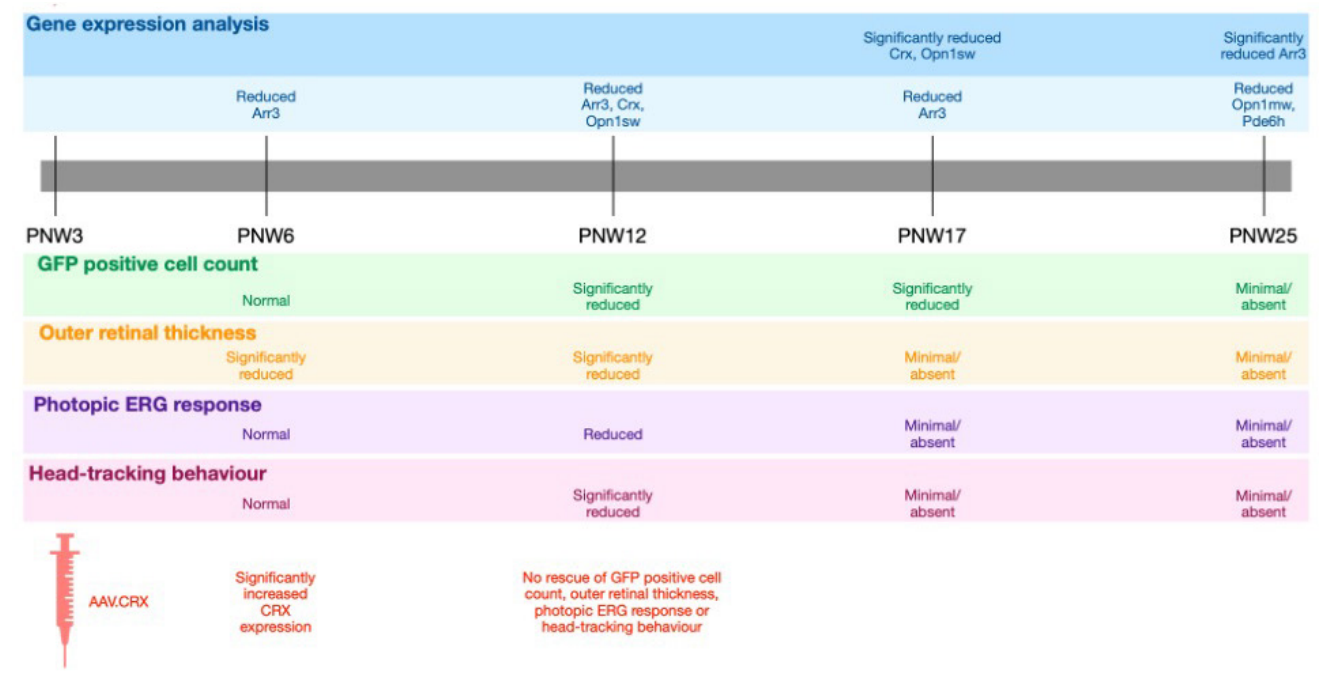

Figure 7. Summary of the changes in gene expression and phenotype over time in $R h o^{-/}$, OPN1-GFPmice. 
The rAAV vector was shown to successfully express the $C R X$ transgene within three weeks of subretinal injection. So too, CRX protein expression was demonstrated in the photoreceptors beginning within weeks and persisting to at least 10 weeks beyond injection. However, the inability of rAAV.CRX to subsequently rescue or prolong cone photosensitivity raises interesting questions about the role of this gene in the loss of cone function. CRX is a transcription factor crucial for the differentiation and maintenance of both rod and cone photoreceptors and its downregulation could reasonably contribute to loss of cone photoreceptor function. Humans with $C R X$ mutations demonstrate cone-rod retinal dystrophy [13]. In mice, Crx synergistically modulates Op1sw and Opn1sw expression in cones [14]. Mice with $C r x$ mutations have down-regulation of genes in the phototransduction cascade, including Opn1sw, Opn1mw, and Arr3 [15]. However, Crx is expressed in both cone and rod photoreceptors. The magnitude of $C r x$ downregulation observed may be mostly caused by rod photoreceptor death, hence the absence of a cone rescue effect from rAAV.CRX injections.

Arr3 transcript levels appeared lower in Rho ${ }^{-/-}$OPN1-GFP mice from PNW6 onwards, but never reached significance. Downregulation of Arr3 may be an early and sustained response to declining cone photosensitivity, thereby prolonging G-protein coupled phototransduction signaling.

The loss of in vivo cone GFP signal in Rho ${ }^{-/-}$OPN1-GFP mice followed a ventral-dorsal pattern (Figure 3a) similar to cone death kinetics shown histologically elsewhere [8]. Notably, the relatively unchanged GFP mRNA expression in Supplementary Figure S1 differed from the clear difference of in vivo GFP protein expression in Figure 3a,d. The differences between transcript and protein detection could be due to the global reduction in protein translation observed in cells undergoing pro-apoptotic stress [16]. The differences may also arise from protein mis-localization and misfolding-and thus loss of GFP fluorescence-observed in cone photoreceptors during degeneration [8].

Opn1mw is expressed throughout the cones of the dorsal and ventral retina, whereas Opn1sw is expressed mainly in the dorsal retinal cones. The significant downregulation of dorsal Opn1sw mRNA differed from the unchanged ventral-dorsal Opn1mw mRNA levels (Figure 1) and, taken together, deviated from the ventral-dorsal pattern of in vivo cone GFP signal loss (Figure 3a). This difference may reflect differential regulation of the transcriptome in S-cones and M-cones, or alternatively suggests that S-cones may be more vulnerable to cell death in RP than M-cones. The unchanged Opn1mw mRNA levels is further evidence that loss of in vivo GFP protein expression in Figure 3a is due to translational mechanisms, not only cone cell loss.

Punzo et al. demonstrated that genes involved in metabolism are greatly down-regulated across multiple mouse models of RP. In particular, insulin/mTOR glucose metabolism pathways are most affected [8]. Similarly, Rod derived Cone Viability Factor (RdCVF) deficiency accelerates cone death in RP rodent models [17], whilst RdCVF supplementation stimulates aerobic glycolysis in cones [18]. The work on insulin/mTOR and RdCVF both converge on the central importance of metabolic starvation in cone photoreceptor death in RP. Both papers identify the high energetic demands of photoreceptor outer segment turnover as early casualties of starving photoreceptors. Our data confirms this negative impact of metabolic starvation on cone opsin transcripts, as well as reduced translation and function of cone proteins such as GFP.

The further characterisation and treatment of upstream common causes-such as metabolic starvation-appear more promising than addressing cone photoreceptor specific transcriptome changes. Developing cone-specific therapies remain important until the wider search for effective genetic and molecular therapies for rod rescue in RP is successful.

\section{Materials and Methods}

\subsection{Mice and Breeding}

In order to study the effect of rod degeneration on the cone phototransduction cascade, the $\mathrm{Rho}^{-/}$ mouse model of RP also expressed GFP in a subset of cone photoreceptors. This GFP expression provided a control for any potential decline in total retinal cone cell count. 
All animals used in this study were treated humanely in accordance with the UK Home Office Regulations and the ARVO statement for the use of animals in ophthalmic and visual research. Animal ethics were approved under UK Home Office project license (PPL) and were also approved by the Oxford animal and welfare review board (PPL 30/2808 from 21 December 2010 to 21 December 2015 and PPL 30/3363 from 21 December 2015 to 21 December 2020). Animals were housed in a 12:12h light-dark cycle. $R h o^{t m 1 P h m}$ mice (herein known as $R h o^{-/-}$mice) have targeted disruption of the Rhodopsin gene, resulting in rod degeneration [10]. $\mathrm{Tg}$ (OPN1LW-EGFP)85933Hue mice express enhanced GFP in a subset of cone photoreceptors and are herein known as OPN1-GFP mice [19]. $\mathrm{Tg}$ (Nrl-EGFP)1Asw mice express enhanced GFP only in the rod photoreceptors and are herein known as Nrl-GFP mice [20]. All mice were genotyped using the published PCR protocols or CSLO screening around the age of weaning. OPN1-GFP breeders were crossed with $R \mathrm{ho}^{-/-}$mice to produce F1 progeny with the RP phenotype and GFP expression in the cone photoreceptors (Rho-/-OPN1-GFP mice). $\mathrm{Nrl}$-GFP breeders were crossed with $\mathrm{Rho}^{-/-}$mice to produce F1 progeny with the RP phenotype and GFP expression in rod photoreceptors.

\subsection{Electroretinography}

As a means of assessing cone electrophysiological function during the period of cone photosensitivity loss, electroretinography (ERG) was performed on anaesthetized mice. Mice were positioned on a heated mat in front of the testing console (Colordome Electroretinography machine; Diagnosys LLC, Vision Park, Cambridge, UK) and isolated cone function was tested as described elsewhere [12]. Single-flash stimuli after light adaptation consisted of $25(1.5 \mathrm{log}) \mathrm{cd} . \mathrm{s} / \mathrm{m}^{2} ; 20$ responses were averaged, with an ISI of $1 \mathrm{~s}$.

\subsection{Optomotor Response Testing}

As a method of assessing integrated cone function during the period of cone photosensitivity loss, a custom optomotor system was produced, consisting of a rotating cylinder that allowed rotation speed to be specified. The cylinder was lined with a square-wave grating pattern of vertical black and white stripes, with a spatial frequency of the grating pattern of 0.1 cycles per degree. The test was performed under photopic conditions: the chamber was illuminated from above with a halogen white light source such that the illumination measured at the position of the animal was 2574 lux. To isolate cone responses, mice were light-adapted on the elevated testing platform for five minutes beforehand and then their head-tracking response to the rotating drum testing protocol quantified as described elsewhere [21].

\subsection{Confocal Scanning Laser Ophthalmoscopy (cSLO) and Optical Coherence Tomography (OCT)}

To accurately measure the rod degeneration and any decline in cone photoreceptor cell counts over time, the retinal phenotype was assessed in vivo using confocal scanning laser ophthalmoscopy and spectral domain optical coherence tomography (Spectralis HRA; Heidelberg Engineering, Heidelberg, Germany) as previously described [22]. A standardized region of interest was sampled from the en face fundus images captured with cSLO (Appendix A) and counted manually using the ImageJ cell counter plugin to determine the surviving proportion of GFP-positive cones. Total retinal and outer retinal thickness measurements from the OCT were made manually using calipers on Heidelberg software. Total retinal thickness was measured from the inner margin of the nerve fiber layer to the inner margin of the RPE. Outer retinal thickness was measured from the inner margin of the outer nuclear layer to the inner margin of the RPE. 


\section{5. mRNA Extraction and cDNA Reverse Transcription from Retinal Tissue}

To reliably isolate the retinal transcriptome for analysis at the desired timepoints, groups of animals were euthanized at postnatal week (PNW) 2, 6, 12, 17 or 25, the whole neurosensory retina of each eye was harvested by dissection and stored in RNAlater (Thermo Fisher Scientific, Waltham, MA, USA) at $-20{ }^{\circ} \mathrm{C}$. Fluorescence-activated cell sorting (FACS) was avoided to prevent cone cell loss and processing-induced changes in the cone transcriptome. RNA was extracted from the retinas using the manufacturer's instructions for the RNeasy mini kit (QIAgen, Manchester, UK) and the recommended on-column DNase digest with the RNase-Free DNase set (QIAgen, Manchester, UK). The retinal samples were homogenized with a rotor and 30-gauge needle prior to processing. Eluted retinal RNA was reverse transcribed to cDNA using the Superscript III synthesis system (Life Technologies, Paisley, UK) and the included oligo-dT primer. The manufacturer's instructions were used.

\subsection{Transcriptome Analysis Using qPCR}

To measure the changes in expression of genes involved in cone function in the $\mathrm{Rho}^{-/}$ mouse model, custom oligonucleotide primers for qPCR were designed to target six genes of the cone phototransduction cascade: Opn1mws, Opn1sws, Arr3, Pde6h, Cnga3, Cngb3; as well as Crx (Supplementary Table S2). By selecting cone-specific genes, there is no need to remove other cells using FACS, thereby avoiding loss of cells and reducing processing-induced changes in the cone transcriptome. These genes are most relevant because they provide cone photoreceptor function.

Model validation, normalization and reference primer pairs were also designed for GFP and $A c t b$. Four to six pairs for each gene were first tested and optimized using non-degenerate OPN1-GFP mouse retinal cDNA dilution series. The nucleotide sequences of the qPCR primers are provided in Supplementary Table S2; from a list of candidates for each gene, the primer pair with 95-103\% efficiency was chosen for the test experiments.

All reactions used a commercial qPCR kit (SYBR Green PCR Master Mix; Applied Biosystems, Foster City, CA, USA) and $2 \mu \mathrm{M}$ final concentration of each forward and reverse primers. All qPCR experiments were performed in triplicate using a commercial real-time PCR machine (CFX Connect Optics Module, BioRad, Hercules, CA, USA). Reactions were performed with the following settings: an initial denaturation step of $95^{\circ} \mathrm{C}$ for $10 \mathrm{~min}$, followed by 40 cycles of: $95^{\circ} \mathrm{C}$ for $30 \mathrm{~s}$, an annealing temperature of $55^{\circ} \mathrm{C}$ and extension at $72{ }^{\circ} \mathrm{C}$ for $30 \mathrm{~s}$. Values obtained for the target genes were reported using the $2^{-\Delta \Delta C t}$ method [9], as detailed in the worked example in Figure A1. Firstly, test gene $\mathrm{Ct}$ values were normalized to the geometric mean of the two housekeeping genes, $A c t B$ and GFP, to calculate $\Delta \mathrm{Ct}$. This provided a double normalization that accounted for variability Secondly, $\Delta \mathrm{Ct}$ values for each mouse type at each timepoint were compared to the OPN1-GFP mice at PNW2 to calculate $\Delta \Delta \mathrm{Ct}$. Results were interpreted alongside the GFP results to account for the decline in cone numbers.

qPCR analysis of transgene expression in rAAV.CRX treated mice (Figure 5a) was performed with the same method, using custom oligonucleotide primers outlined in Supplementary Figure S3 and Table S2.

\subsection{Recombinant AAV Production and Intraocular Injection}

The most down-regulated gene $(C R X)$ was cloned into an rAAV vector and over-expressed in the retina of $\mathrm{RhO}^{-/-}$mice to assess the effect on prolonging or preserving cone photosensitivity in RP. The individual effects of over-expressing CRX was explored across two rAAV doses. This study used an early practical time point, postnatal day (PND) 21, for subretinal injection in order to maximize the chance of transgene expression prior to endogenous cone gene downregulation.

rAAV2/2.CAG.CRX.WPRE.pA (AAV.CRX) was produced in HEK293T cells. Cultures were transfected with plasmids containing the expression cassette, RepCap and helper sequences. The HEK293T cells were pelleted, lysed, purified using an Iodixanol gradient, and then purified using an Amicon Ultra 100K filter (Merck, Germany). 
The rAAV were validated before in vivo use (Supplementary Figure S3). In vitro expression of transgenic protein was confirmed by transducing confluent HEK293T cells with rAAV. After culture for three days, immunocytochemistry was performed with primary anti-CRX (PA5-32182, Thermo Fisher Scientific, Waltham, MA, USA) antibody. Secondary staining was performed with Alexa-Fluor 568 donkey anti-rabbit (A10042, Thermo Fisher Scientific, Waltham, MA, USA).

rAAV capsid purity was confirmed with SDS-PAGE. The rAAV concentrate was mixed with protein loading buffer (National Diagnostics, Atlanta, GA, USA), heat denatured and separated electrophoretically on a precast gel (Bio-Rad, Hertfordshire, UK). The capsid protein bands were stained using EZBlue (Sigma-Aldrich, Dorset, UK).

Viruses titre was measured using optimised custom qPCR primers targeting CRX (FW-5'-GACAGCAGCAGAAACAGCAG-3' and RC-5'-GGCTCCAGATGGACACAGTG-3'). rAAV was treated with DNAse I (New England Biolabs, Ipswich, MA, USA) before the capsids were denatured by heating. qPCR was performed as described above and the titre was measured against a known dilution series of pAAV.CAG.CRX.WPRE.pA plasmid.

rAAV suspended in phosphate buffered solution (PBS) to give the desired dose in $1.5 \mu \mathrm{L}$ was delivered by subretinal injection to $R h o^{-/}$, OPN1-GFP mice at PND 21. After the onset of anesthesia, the pupil was dilated. A $6 \mathrm{~mm}$ circular glass coverslip (VWR International, East Grinstead, UK) was positioned on a viscous coupling gel (Viscotears liquid gel, $0.2 \mathrm{mg} / \mathrm{g}$ polyacrylic acid; Alcon Laboratories Ltd., Camberley, UK) and the fundus was visualized using an operating microscope (Leica Biosystems, Wetzlar, Germany).

A Nanofil $10 \mu \mathrm{L}$ syringe (World Precision Instruments, Sarasota, FL, USA) was assembled with the Nanofil 35G beveled needle (WPI). $1.5 \mu \mathrm{L}$ of PBS sham or rAAV vector at the chosen titre was delivered by trans-scleral injection into the subretinal space to create a hemiretinal detachment. Antibiotic eye drops (Chloramphenicol 0.5\%; Bausch \& Lomb, Rochester, NY, USA) and Viscotears were applied topically.

\subsection{Immunohistochemistry}

In order to demonstrate successful retinal transduction, as well as accurately examine the localization of the $C R X$ transgene, a subset of injected eyes were collected for immunohistochemistry. Following euthanasia and enucleation, the cornea was excised at the limbus. The zonules were blunt dissected with Vannas scissors and the lens extruded whilst avoiding retinal traction. The eyecups were then transferred to $4 \%(w / v)$ PFA (Thermo Fisher Scientific, Waltham, MA, USA) for 30 min for initial fixation. The eyecups were then sequentially transferred to $10 \%, 20 \%$ and $30 \%$ sucrose and then embedded in OCT compound (VWR International, East Grinstead, UK) and stored at $-80{ }^{\circ} \mathrm{C}$ until sectioning.

Sample blocks were sectioned in $20 \mu \mathrm{M}$ slices at $-22^{\circ} \mathrm{C}$ (Cryotome LSE; Thermo Fisher Scientific, Waltham, MA, USA), placed onto polysine-coated glass slides and allowed to dry overnight. All sections were then permeabilized with dilute Triton- $X$, blocked with donkey serum and incubated with primary anti-CRX (PA5-32182, Thermo Fisher Scientific, Waltham, MA, USA). Secondary staining was performed with Alexa-Fluor 568 donkey anti-rabbit (A10042, Thermo Fisher Scientific, Waltham, MA, USA). The slides were then counter-stained with 4',6-diamidino-2-phenylindole (DAPI; Invitrogen, Carlsbad, CA, USA). Coverslips were applied with ProLong Diamond Antifade Mountant (Life Technologies, Paisley, UK).

Retinal sections were viewed on a confocal microscope (LSM710; Zeiss, Oberkochen, Germany). Fluorescent cells were located using fluorescence illumination before taking a series of $0.5 \mu \mathrm{m}$ thickness overlapping XY optical sections. Fluorescence of Hoechst, GFP, and Alexa 568 were sequentially excited and a stack built. Image processing was performed using Volocity (Perkin-Elmer, Waltham, MA, USA) and ImageJ (version 1.43; National Institutes of Health, https://imagej.nih.gov/ij) [23]. 


\subsection{Statistical Analysis}

Statistical analysis was performed using R software (v3.5.1) [24]. Hierarchical linear and non-linear modelling was performed using the nlme package $[25,26]$.

Supplementary Materials: Supplementary Materials can be found at http://www.mdpi.com/1422-0067/21/17/ 6055/s1.

Author Contributions: Conceptualization, M.M.H., M.E.M., A.R.B., S.A.A. and R.E.M.; data curation, M.M.H.; formal analysis, M.M.H., M.E.M. and R.E.M.; funding acquisition, R.E.M.; investigation, M.M.H.; methodology, M.M.H., M.E.M., A.R.B., M.I.P., S.A.A. and R.E.M.; project administration, M.M.H.; resources, M.M.H., M.E.M., A.R.B., M.I.P. and R.E.M.; software, M.M.H. and A.R.B.; supervision, S.A.A. and R.E.M.; validation, M.M.H., M.E.M. and A.R.B.; visualization, M.M.H.; writing—original draft, M.M.H.; writing—review \& editing, M.M.H., M.E.M., A.R.B., M.I.P., S.A.A. and R.E.M. All authors have read and agree to the published version of the manuscript.

Funding: Royal College of Surgeons of Edinburgh, Medical Research Council DPFS and the Rhodes Trust.

Conflicts of Interest: The authors declare no conflict of interest. The funders had no role in the design of the study; in the collection, analyses, or interpretation of data; in the writing of the manuscript, or in the decision to publish the results.

\section{Abbreviations}

$\begin{array}{ll}\text { cSLO } & \text { Confocal scanning laser ophthalmoscope } \\ \text { eNpHR } & \text { Enhanced Halorhodopsin } \\ \text { ERG } & \text { Electroretinography } \\ \text { FACS } & \text { Fluorescence-activated cell sorting } \\ \text { GFP } & \text { Green fluorescent protein } \\ \text { INL } & \text { Inner nuclear layer } \\ \text { IRD } & \text { Inherited retinal dystrophy } \\ \text { OCT } & \text { Optical coherence tomography } \\ \text { OMR } & \text { Optomotor response } \\ \text { ONL } & \text { Outer nuclear layer } \\ \text { PBS } & \text { Phosphate buffered solution } \\ \text { PNW } & \text { Postnatal week } \\ \text { PND } & \text { Postnatal day } \\ \text { rAAV } & \text { Recombinant adeno-associated virus } \\ \text { RP } & \text { Retinitis Pigmentosa } \\ \text { RPE } & \text { Retinal pigment epithelium } \\ \text { RdCVF } & \text { Rod-derived Cone Viability Factor }\end{array}$

\section{Appendix A}

(a) Mean housekeeping (hk) $\mathrm{Ct}=\operatorname{mean}(\operatorname{Act} B \mathrm{Ct}+\mathrm{GFP} \mathrm{Ct})$

(b) $\Delta \mathrm{Ct}=\mathrm{Crx} \mathrm{Ct}-$ mean hk Ct

(c) $\Delta \Delta \mathrm{Ct}=\operatorname{mean}\left(R h 0^{\%}\right.$, OPN1.GFP $\left.\Delta \mathrm{Ct}\right)-\operatorname{mean}($ OPN1.GFP $\Delta \mathrm{Ct})$

\begin{tabular}{|c|c|c|c|c|c|c|c|c|c|c|}
\hline 4 & A & в & c & D & E & $\mathrm{F}$ & G & H & 1 & 1 \\
\hline 1 & Sample ID & Gene & ActB Ct & GFPCt & Mean $\mathrm{hk} \mathrm{Ct}$ & $\mathrm{Crx} \mathrm{Ct}$ & $\Delta \mathrm{Ct}$ & Mean $\Delta C \mathrm{Ct}$ & $\Delta \Delta \mathrm{Ct}$ & $2^{\wedge}-\Delta \Delta C t$ \\
\hline 2 & 6w: OPN1-GFP \#1 & $\mathrm{Crx}$ & 17.190 & 18.117 & 17.653 & 15.652 & -2.001 & & & \\
\hline 3 & 6w: OPN1-GFP \#2 & Crx & 17.228 & 18.047 & 17.637 & 15.774 & -1.863 & & & \\
\hline 4 & 6w: OPN1-GFP \#3 & $\mathrm{Crx}$ & 16.823 & 17.604 & 17.214 & 16.461 & -0.752 & -1.539 & & \\
\hline 5 & & & & & & & & & & \\
\hline 6 & 6w: Rho-/-\#1 & $\mathrm{Crx}$ & 16.529 & 18.502 & 17.515 & 17.378 & -0.137 & & & \\
\hline 7 & 6w: Rho-/-\#2 & Crx & 16.146 & 17.441 & 16.794 & 15.681 & -1.113 & & & \\
\hline 8 & 6w: Rho- $/-\# 3$ & crx & 17.122 & 18.683 & 17.903 & 17.342 & -0.560 & & & \\
\hline 9 & 6w: Rho-/-\#4 & Crx & 15.839 & 17.604 & 16.721 & 15.355 & -1.366 & & & \\
\hline 10 & 6w: Rho-/-\#5 & Crx & 15.741 & 18.116 & 16.929 & 17.054 & 0.125 & -0.610 & 0.929 & 0.525 \\
\hline
\end{tabular}

Figure A1. Detailed example of the $\Delta \Delta \mathrm{Ct}$ normalization of cone gene qPCR data using the published method [9]. The example gene here is $C r x$ at the PNW6 time point. 
The first equation (a) describes the calculation of the mean housekeeping (hk) Ct value as the mean of the $A c t B$ and GFP housekeeping genes. Equation (b) describes the first delta $(\Delta)$ normalization of the test gene ( $\mathrm{Cr} x$; column F) by subtraction of the mean housekeeping $\mathrm{Ct}$ (Mean hk Ct: Column E), to produce the $\Delta \mathrm{Ct}$ values in column $\mathrm{G}$. The final equation (c) describes the calculation of the $\Delta \Delta \mathrm{Ct}$ value from the $\triangle \mathrm{Ct}$ values of the OPN1-GFP and $\mathrm{Rho}^{-/}$, OPN1-GFP mice. The final calculated $2^{-\triangle \Delta \mathrm{Ct}}$ values are represented graphically in Figure $2 b$, with the OPN1-GFP $2^{-\Delta \Delta C t}$ represented as a dotted line at $\mathrm{y}=1$.

\section{References}

1. Haim, M. Epidemiology of retinitis pigmentosa in Denmark. Acta Ophthalmol. Scand. Suppl. 2002, 1-34. [CrossRef] [PubMed]

2. Mustafi, D.; Engel, A.H.; Palczewski, K. Structure of cone photoreceptors. Prog. Retin. Eye Res. 2009, 28, 289-302. [CrossRef] [PubMed]

3. Schnapf, J.L.; Kraft, T.W.; Baylor, D.A. Spectral sensitivity of human cone photoreceptors. Nature 1987, 325, 439-441. [CrossRef] [PubMed]

4. Blackshaw, S.; Fraioli, R.E.; Furukawa, T.; Cepko, C.L. Comprehensive analysis of photoreceptor gene expression and the identification of candidate retinal disease genes. Cell 2001, 107, 579-589. [CrossRef]

5. Corbo, J.C.; Myers, C.A.; Lawrence, K.A.; Jadhav, A.P.; Cepko, C.L. A typology of photoreceptor gene expression patterns in the mouse [Internet]. Proc. Natl. Acad. Sci. USA 2007, 104, 12069-12074. [CrossRef]

6. Znoiko, S.L.; Rohrer, B.; Lu, K.; Lohr, H.R.; Crouch, R.K.; Ma, J.-X. Downregulation of cone-specific gene expression and degeneration of cone photoreceptors in the Rpe65-/- mouse at early ages. Investig. Ophthalmol. Vis. Sci. 2005, 46, 1473-1479. [CrossRef]

7. Daiger, S.P.; Rossiter, B.; Greenberg, J.; Christoffels, A.; Hide, W. Data services and software for identifying genes and mutations causing retinal degeneration. Investig. Ophthalmol. Vis. Sci. 1998, 39, S295.

8. Punzo, C.; Kornacker, K.; Cepko, C.L. Stimulation of the insulin/mTOR pathway delays cone death in a mouse model of retinitis pigmentosa. Nat. Neurosci. 2009, 12, 44-52. [CrossRef]

9. Livak, K.J.; Schmittgen, T.D. Analysis of relative gene expression data using real-time quantitative PCR and the 2(-Delta Delta C(T)) Method. Methods 2001, 25, 402-408. [CrossRef]

10. Humphries, M.M.; Rancourt, D.; Farrar, G.J.; Kenna, P.; Hazel, M.; Bush, R.A.; Sieving, P.A.; Sheils, D.M.; McNally, N.; Creighton, P.; et al. Retinopathy induced in mice by targeted disruption of the rhodopsin gene. Nat. Genet. 1997, 15, 216-219. [CrossRef]

11. Beck, S.C.; Schaeferhoff, K.; Michalakis, S.; Fischer, M.D.; Huber, G.; Rieger, N.; Riess, O.; Wissinger, B.; Biel, M.; Bonin, M.; et al. In vivo analysis of cone survival in mice. Investig. Ophthalmol. Vis. Sci. 2010, 51, 493-497. [CrossRef] [PubMed]

12. Hassall, M.M.; Barnard, A.R.; Orlans, H.O.; McClements, M.E.; Charbel Issa, P.; Aslam, S.A.; MacLaren, R.E. A Novel Achromatopsia Mouse Model Resulting From a Naturally Occurring Missense Change in Cngb3. Investig. Ophthalmol. Vis. Sci. 2018, 59, 6102-6110. [CrossRef] [PubMed]

13. Swain, P.K.; Chen, S.; Wang, Q.L.; Affatigato, L.M.; Coats, C.L.; Brady, K.D.; Fishman, G.A.; Jacobson, S.G.; Swaroop, A.; Stone, E.; et al. Mutations in the cone-rod homeobox gene are associated with the cone-rod dystrophy photoreceptor degeneration. Neuron 1997, 19, 1329-1336. [CrossRef]

14. Hennig, A.K.; Peng, G.-H.; Chen, S. Regulation of photoreceptor gene expression by Crx-associated transcription factor network. Brain Res. 2008, 1192, 114-133. [CrossRef] [PubMed]

15. Ruzycki, P.A.; Tran, N.M.; Kefalov, V.J.; Kolesnikov, A.V.; Chen, S. Graded gene expression changes determine phenotype severity in mouse models of CRX-associated retinopathies. Genome Biol. 2015, 16, 171. [CrossRef]

16. Lasfargues, C.; Martineau, Y.; Bousquet, C.; Pyronnet, S. Changes in translational control after pro-apoptotic stress. Int. J. Mol. Sci. 2012, 14, 177-190. [CrossRef]

17. Cronin, T.; Raffelsberger, W.; Lee-Rivera, I.; Jaillard, C.; Niepon, M.-L.; Kinzel, B.; Clérin, E.; Petrosian, A.; Picaud, S.; Poch, O.; et al. The disruption of the rod-derived cone viability gene leads to photoreceptor dysfunction and susceptibility to oxidative stress. Cell Death Differ. 2010, 17, 1199-1210. [CrossRef]

18. Aït-Ali, N.; Fridlich, R.; Millet-Puel, G.; Clérin, E.; Delalande, F.; Jaillard, C.; Blond, F.; Perrocheau, L.; Reichman, S.; Byrne, L.C.; et al. Rod-derived cone viability factor promotes cone survival by stimulating aerobic glycolysis. Cell 2015, 161, 817-832. [CrossRef] 
19. Fei, Y.; Hughes, T.E. Transgenic expression of the jellyfish green fluorescent protein in the cone photoreceptors of the mouse. Vis. Neurosci. 2001, 18, 615-623. [CrossRef]

20. Akimoto, M.; Cheng, H.; Zhu, D.; Brzezinski, J.A.; Khanna, R.; Filippova, E.; Oh, E.C.T.; Jing, Y.; Linares, J.-L.; Brooks, M.; et al. Targeting of GFP to newborn rods by Nrl promoter and temporal expression profiling of flow-sorted photoreceptors. Proc. Natl. Acad. Sci. USA 2006, 103, 3890-3895. [CrossRef]

21. Lipinski, D.M.; Barnard, A.R.; Singh, M.S.; Martin, C.; Lee, E.J.; Davies, W.I.L.; MacLaren, R.E. CNTF Gene Therapy Confers Lifelong Neuroprotection in a Mouse Model of Human Retinitis Pigmentosa. Mol. Ther. 2015, 23, 1308-1319. [CrossRef] [PubMed]

22. Charbel Issa, P.; Singh, M.S.; Lipinski, D.M.; Chong, N.V.; Delori, F.C.; Barnard, A.R.; MacLaren, R.E. Optimization of in vivo confocal autofluorescence imaging of the ocular fundus in mice and its application to models of human retinal degeneration. Investig. Ophthalmol. Vis. Sci. 2012, 53, 1066-1075. [CrossRef] [PubMed]

23. Schneider, C.A.; Rasband, W.S.; Eliceiri, K.W. NIH Image to ImageJ: 25 years of image analysis. Nat. Methods 2012, 9, 671-675. [CrossRef] [PubMed]

24. R Core Team. R: A Language and Environment for Statistical Computing; R Foundation for Statistical Computing: Vienna, Austria, 2017; Available online: https://www.R-project.org/ (R version 3.5.1) (accessed on 2 July 2018).

25. Pinheiro, J.; Bates, D.; DebRoy, S.; Sarkar, D.; R Core Team. nlme: Linear and Nonlinear Mixed Effects Models. 2017. Available online: https://CRAN.R-project.org/package=nlme (nlme version: 3.1-137) (accessed on 7 April 2018).

26. Pinheiro, J.C.; Bates, D.M. Linear Mixed-Effects Models: Basic Concepts and Examples. In Mixed-Effects Models in S and S-PLUS; Springer: New York, NY, USA, 2000; pp. 3-56.

(C) 2020 by the authors. Licensee MDPI, Basel, Switzerland. This article is an open access article distributed under the terms and conditions of the Creative Commons Attribution (CC BY) license (http://creativecommons.org/licenses/by/4.0/). 